Check for updates

London

Cite this as: BMJ 2020;371:m4240 http://dx.doi.org/10.1136/bmj.m4240 Published: 30 October 2020

\section{General practice: BMA reiterates call for extra support as workload mounts}

\author{
Ingrid Torjesen
}

The BMA has asked NHS England to provide more financial support for general practice in dealing with a burgeoning workload from rising covid-19 cases, as well as from non-covid patients as hospitals cancel routine procedures and practices have to pick up the strain.

At the same time, general practices are facing increased costs and stresses. They are providing covid secure premises and working practices while also facing workforce shortages as growing numbers of staff test positive for covid-19 or have to take time off for caring responsibilities or self-isolation.

Extra financial support was available through a covid support fund set up by NHS England during the first wave of the pandemic, but it ran only until 31 July, except for care home work, which was covered until 30 September. Some additional funding to help practices deal with covid-19 was then made available until 30 September through primary care networks.

The BMA has called for the covid support fund to be expanded, for an extension until March 2021, and for other measures to support general practice, including provision of free personal protective equipment. ${ }^{1}$

\section{Early winter workloads}

Krishna Kasaraneni, of the BMA’s General Practitioners Committee, said, "As covid infections rise, practices in the north of England and across the country are once again coming under intense pressure. Nobody should doubt the commitment of GPs to serve their communities, but to do this effectively in a time of crisis they need more support from government and the NHS leadership-and for this support to be delivered without further delay."

GPs in tier 3 levels in northwest England have warned that their winter workloads have come six weeks earlier this year, and rising workloads are being experienced elsewhere in the country. ${ }^{2}$

Greg Place, chair of the local medical committee in Nottinghamshire, which will enter tier 3 covid-19 restrictions on 30 October, said that rising cases had led hospitals to cancel a lot of routine work. Nottingham University Hospitals NHS Trust has suspended all non-urgent work and appointments until 6 November.

"It does feel as if it's going back to spring, where there was a moratorium on quite a lot of the routine work and a lot of it was being left in general practice to hold and cope with," he said. While GPs understood that hospitals had to cancel routine work, he added, those GPs needed support to pick up the pieces.

"In general practice, we feel less well

supported-we're not able to change what we do in "carry on coping." Secondary care providers could "close their doors," and some of their capital debt had been taken away "with one swipe of the pen," he explained.

"[GPs] don't have the same degree of financial support up front," he said. The fact that expenses would not necessarily be reimbursed from 1 October "was really not a great message."

Place has recently been the last clinician standing at his practice, after it was hit by an outbreak of covid-19. Three members of staff went down with the infection, so everyone working there was swabbed, which identified six more positive cases.

For six hours the practice had to "almost close its doors." It had two staff members fielding calls, and most patients were managed remotely, but some needed to be seen face to face.

The surgery kept running while a deep clean was conducted room by room, Place explained. He said, "We were creative in how we used the space available and tried to see the bare minimum of patients. We did a few more house calls that day, because it was just more practical to go out and see the patients.”

lacobucci G. Covid-19: GPs need extra support to withstand second wave, BMA warns. BM/2020;371:m3806. doi: 10.1136/bmj.m3806 pmid: 33004345

2 Torjesen I. Winter pressure has hit GPs and hospitals in tier 3 areas six weeks earlier than normal. BMJ2020;371:m4156. doi: 10.1136/bmj.m4156 pmid: 33109686 the same way," said Place, so it was a question of 